\title{
Enhancement in efferocytosis of oxidized low-density lipoprotein-induced apoptotic RAW264.7 cells through Sirt1-mediated autophagy
}

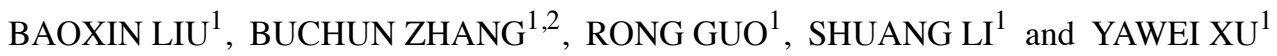 \\ ${ }^{1}$ Department of Cardiology, Shanghai Tenth People's Hospital, Tongji University School of Medicine, Shanghai 200072; \\ ${ }^{2}$ Department of Cardiology, The Affiliated Hospital of Xuzhou Medical College, Xuzhou, Jiangsu 221002, P.R. China
}

Received September 8, 2013; Accepted December 16, 2013

DOI: $10.3892 /$ ijmm.2013.1609

\begin{abstract}
Macrophages play a key role in atherosclerotic plaque formation and rupture. These phagocytic cells are important in the scavenging of modified lipoproteins, unwanted or dead cells and cellular debris through efferocytosis. Sirtuin1 (Sirt1), a member of the conserved sirtuin family and a key regulator in the progression of atherosclerosis exerts protective effects by regulating autophagy, a well-known survival mechanism. Inhibition of autophagy may also result in defective efferocytosis. This study aimed to investigate the effect of Sirtl on the efferocytosis of oxidized low-density lipoprotein (ox-LDL)-induced apoptotic RAW264.7 cells through upregulation of autophagy. The apoptotic cells were incubated with high and low concentrations of Sirtl activator resveratrol (RSV) and Sirt1 inhibitor nicotinamide (NAM) as well as autophagy inhibitor 3-methyladenine (3-MA) + low concentration RSV. Apoptosis was determined by flow cytometry (FCM) of annexin-V/propidium iodide (AV/PI) dual staining. Total proteins were extracted and protein levels were detected through western blot analysis. The ox-LDL uptake and efferocytosis of apoptotic RAW264.7 cells were detected by oil red $\mathrm{O}$ staining and calculation of the phagocytic index of apoptotic RAW264.7 cells. The expression of Sirt1 and autophagy marker proteins was simultaneously increased with the stimulation of low concentration RSV (all $\mathrm{P}<0.05)$ and decreased in low and high NAM groups (all $\mathrm{P}<0.05$ ), compared with the control group. Efferocytosis was highest in the low concentration RSV group $(\mathrm{P}<0.001)$ and relatively lower in the low and high concentration NAM groups (both $\mathrm{P}<0.05)$ compared with the control group, which was similar
\end{abstract}

Correspondence to: Dr Buchun Zhang or Dr Yawei Xu, Department of Cardiology, Shanghai Tenth People's Hospital, Tongji University School of Medicine, 301 Middle Yanchang Road, Shanghai 200072, P.R. China

E-mail: drzhangbc@sina.com

E-mail: xuyaweicn@sina.com

Key words: Sirt1, RAW264.7, autophagy, efferocytosis, apoptosis, atherosclerosis to the change in the expression of Sirtl and autophagy marker proteins. The results showed that the efferocytosis of apoptotic RAW264.7 cells was significantly improved with the upregulation of Sirt1-mediated autophagy. Therefore, Sirt1 may serve as a novel therapeutic target for the treatment of atherosclerosis.

\section{Introduction}

Atherosclerosis is a chronic immuno-inflammatory disease with high morbidity and atherosclerosis-related cardiovascular diseases are the leading cause of mortality worldwide (1). The destabilization and rupture of atherosclerotic plaques is the main pathological basis of acute cardiovascular disease events without effective treatments. Macrophages play a key role in each stage of atherosclerosis (2). Stimulation of high levels of oxidized low-density lipoprotein (ox-LDL), led to the monocyte-derived macrophages become lipid-laden and are eventually transformed into foam cells. A central feature of atherosclerosis is the accumulation of foam cells in the lesion and, notably macrophage recruitment into plaques is critical for, and increases with, disease progression (3-5). ox-LDL is also a potential inducer of cell apoptosis in atherosclerosis. Previous studies have demonstrated that ox-LDL induced apoptosis in a variety of tissues and cells, including endothelial cells (ECs), vascular smooth muscle cells (VSMCs) and macrophages (6-9). Apoptosis of macrophages and VSMCs in atherosclerotic plaques is thought to lead to increased necrotic core formation, inflammation, plaque rupture and atherothrombosis $(10,11)$. In human atherosclerotic plaques, apoptosis of macrophages is detected during all stages, which occurs more frequently compared with apoptosis of the VSMCs. Accumulating evidence has shown that the phagocytic clearance of apoptotic cells, or 'efferocytosis' in macrophages is effective in the early stage of atherosclerosis, whereas efferocytosis in advanced atherosclerosis becomes defective, which is causally linked to the progression of atherosclerosis (12). Therefore, the enhancement in efferocytosis by drugs or other methods in macrophages potentially contributes to the inhibition of atherosclerotic plaques progression and reduction of acute coronary events.

Results of recent studies on macrophage autophagy have shown a novel pathway through which these cells contribute to vascular disease (13-16). Autophagy may be a new target 
for therapeutic utility in atherosclerosis. Originally described as 'self-eating' in the 1960s, autophagy is an evolutionarily conserved controlled cellular catabolic process that mediates the degradation of altered and damaged proteins and organelles. The cellular symbol of autophagy is the formation of characteristic double-membrane vesicles, known as autophagosomes. The origins of this structure remain to be elucidated, although it may be generated from multiple sources including the endoplasmic reticulum $(17,18)$, the outer mitochondrial membrane $(17,19)$, and the plasma membrane $(20,21)$. The autophagosomes are targeted to lysosomes to form single-membraned submicroscopic vesicles termed autolysosomes with degradative capacity. The altered and damaged proteins and organelles were contained in autolysosomes and were eliminated by a series of lysosomal enzymes. Autophagy exerts a protective effect in nutrients generating and maintaining survival (22). Recent evidence suggested that maintenance of basal autophagy in macrophages was useful in the clearance of apoptotic and necrotic cells, which may enhance the efferocytosis of apoptotic macrophages (23-25).

The sirtuins are a family of nicotinamide adenine dinucleotide (NAD)-dependent deacetylases that have been linked to the regulation of life span initially found in yeast cells. Sirtuin1 (Sirt1) is the closest relative of yeast Sir2 in mammalian cells which play important roles in multiple disease-related pathways such as cell cycle regulation, cell apoptosis and migration (26). Resveratrol (3,4',5-trihydroxy-trans-stilbene, RSV), a polyphenolic phytoalexin, is a potent activator of Sirt1. Nicotinamide (NAM), the precursor for the synthesis of $\mathrm{NAD}^{+}$, has been recognized as an inhibitor of Sirt1. Previous results indicated that RSV suppressed atherosclerosis in hypercholesterolemic rabbits and endothelium-specific overexpression of Sirt1 decreased atherosclerosis in apolipoprotein E-deficient $\left(\mathrm{apoE}^{--}\right)$mice. Moreover, Sirt1 modulated neointima formation following vascular injury in mice (27-30). Sirtl is considered a novel target in the prevention of atherosclerosis by regulating lipid metabolism, promoting endothelial survival and improving endothelial function, repressing vascular smooth muscle cell migration and proliferation and most importantly, inducing cellular autophagy (31-34). Sirt1 was reported to prevent atherosclerosis by potentially regulating the degree of autophagy to match current cellular needs with real-time metabolic status (35).

Focus on VSMCs and ECs has been given in previous investigations on autophagy $(23,36,37)$. Transmission electron microscopy (TEM) of VSMCs in the fibrous cap of experimental or human plaques reveals features of autophagy such as the formation of myelin figures (36). Moreover, experimental exposure of endothelial cells directly to ox-LDL strongly enhanced autophagy compared with exposure to LDL only, indicating that autophagy may contribute to the degradation of ox-LDL $(37,38)$. Autophagy has also been reported to regulate intracellular lipid metabolism to avoid the formation of foam cells $(39,40)$. As recently reviewed $(41,42)$, lipophagy, a special type of autophagy, contributes to cholesterol egress from lipid-laden cells to high-density lipoprotein (HDL) via lysosomal lipases. Autophagy can play a role in the hydrolysis of stored cholesterol droplets in macrophages, thus facilitating cholesterol efflux (43). The function of macrophage autophagy in atherosclerosis has been complicated by the strong phagocytic activity of these cells. Currently, few studies have focused on the enhancement in efferocytosis of apoptotic macrophages through Sirtl-mediated autophagy. However, autophagy is a 'double-edged sword'. The general consensus is that basal autophagy can protect plaque cells against oxidative stress by degrading damaged intracellular material and promoting cell survival, and excessive stimulation of autophagy may cause autophagic cell death, leading to reduced synthesis of collagen, thinning of the fibrous cap, plaque destabilization, lesional thrombosis, and acute clinical events $(44,23,24)$. Thus the aim of this study was to determine whether there was a connection between enhancement in efferocytosis of apoptotic macrophages and autophagy mediated by Sirt1.

\section{Materials and methods}

Reagents and antibodies. A Cell Counting Kit-8 (CCK-8) was purchased from Dojindo Laboratories (Kumamoto, Japan). ox-LDL was purchased from AbD Serotec (Kidlington, Oxford, UK). Oil red O staining, 5(6)-carboxyfluorescein diacetate N-succinimidyl ester (CFSE) staining, Sirt1-activator RSV, Sirt1-inhibitor NAM and autophagy-inhibitor 3-methyladenine (3-MA) were purchased from Sigma-Aldrich Co. (St. Louis, MO, USA). The anti-Sirt1 antibody was obtained from Cell Signaling (Beverly, MA, USA). The anti-light chain (LC) 3, anti-Atg5 and anti-Atg7 antibodies were obtained from Epitomics (Burlingame, CA, USA). Horseradish peroxidase-linked anti-rabbit, anti-mouse secondary antibodies and RIPA buffer were obtained from Santa Cruz Biotechnology, Inc. (Santa Cruz, CA, USA).

Cell culture and experimental design. A mouse macrophage-like RAW264.7 cell line was purchased from the Cell Bank of the Shanghai Institutes for Biological Sciences, Chinese Academy of Sciences. The cells were cultured in Dulbecco's modified Eagle's medium (DMEM, Gibco, NY, USA), which contained $5 \mathrm{mM}$ glucose, and were supplemented with 10\% fetal bovine serum (FBS) (Gibco) and 1\% penicillin/ streptomycin at $37^{\circ} \mathrm{C}$ with $5 \% \mathrm{CO}_{2}$ in a humidified atmosphere. The cells were passaged every 2-3 days and then placed into 6-well plates with slides at a density of $4 \times 10^{5}$ cells $/ \mathrm{cm}^{2}$ and made apoptotic by incubation with ox-LDL. The optimal concentration and time point of ox-LDL were analyzed using western blotting of Sirt1 and the autophagy marker proteins. The apoptotic cells were randomly divided into the following groups: i) control group, only apoptotic cells, ii) low concentration RSV group: apoptotic cells incubated with RSV of low concentration, iii) high concentration RSV group: apoptotic cells incubated with RSV of high concentration, iv) low concentration NAM group: apoptotic cells incubated with NAM of low concentration, v) high concentration NAM group: apoptotic cells incubated with NAM of high concentration, vi) 3-MA + low concentration RSV group: the apoptotic cells were pretreated with $10 \mathrm{mM} 3-\mathrm{MA}$ for $2 \mathrm{~h}$, and then incubated with low concentration RSV. The low and high concentration of RSV and NAM were assayed from the cell proliferation of RAW264.7 incubation with RSV and NAM for $24 \mathrm{~h}$.

Protein extraction and western blot analysis. Total proteins were obtained by rinsing treated cells with ice-cold 
phosphate-buffered saline (PBS), and lysing in lysis buffer (10 mM Tris pH 7.4, $20 \mathrm{mM} \mathrm{NaCl,} 5 \mathrm{mM} \mathrm{MgCl} 2,0.5 \% \mathrm{NP}-40$ and $0.1 \mathrm{mM}$ PMSF). The extracts were then centrifuged at $12,000 \mathrm{x} \mathrm{g}$ for $10 \mathrm{~min}$ at $4^{\circ} \mathrm{C}$, and the clear supernatants containing total protein were collected. The protein concentration was measured with the Bio-Rad protein assay (Hercules, CA, USA), an equal amount of protein was separated on SDS-polyacrylamide gel electrophoresis and transferred to nitrocellulose membranes. After blocking with 5\% non-fat milk, the membranes were incubated overnight with the previously mentioned first antibodies at $4^{\circ} \mathrm{C}$. The membranes were then incubated with the appropriate secondary antibodies, and the bands were detected by enhanced chemiluminescence. The band density value was quantified using the ImageJ image processing program. Since the extent of conversion of LC3-I to LC3-II is correlated with the level of autophagy, LC3-I and LC3-II were detected by western blot analysis, and the conversion of LC3 was demonstrated by LC3-II/LC3-I ratio. The LC3-II/LC3-I ratio was calculated as follows: LC3-II/LC3-I ratio = the band density of LC3-II/the band density of LC3-I. We also detected the expression of two separate autophagy proteins, Atg5 and Atg7, which were ultimately required for the formation of the autophagosome and the subsequent induction of autophagy (45-47).

Cell Counting Kit-8 assay. Cell proliferation was assayed using a CCK-8 assay. Cell suspension (100 $\mu \mathrm{l})$ of RAW264.7 cells seeded in 96-well plates at a density of $1 \times 10^{5}$ cells/well was performed. RAW264.7 cells were then treated with RSV or NAM. The final concentrations of RSV were 50, 25, 12.5 , 5 and $0 \mu \mathrm{M}$, respectively. The final concentrations of NAM were $80,40,20,10,5$ and $0 \mathrm{mM}$, respectively. Each group was prepared with five parallel wells and incubated at $37^{\circ} \mathrm{C}, 5 \%$ $\mathrm{CO}_{2}$, for $24 \mathrm{~h}$. At the end of the culture period, CCK- 8 was added to each well according to the manufacturer's instructions at a final concentration of $0.5 \mathrm{mg} / \mathrm{ml}$ for $3 \mathrm{~h}$. The absorbance was measured with an enzyme calibrator at 450 and $650 \mathrm{~nm}$ and optical density (OD) values were measured. Experiments were repeated three times.

Oil red $O$ staining. The RAW264.7 cells, measured for lipid accumulation through staining of ox-LDL with oil red $\mathrm{O}$, were placed in 6-well plates with slides at a density of $4 \times 10^{5}$ cells $/ \mathrm{cm}^{2}$ and followed with the aforementioned treatments. At the end of the treatment period, the cells were rinsed with PBS and fixed with $10 \%$ formalin for $5 \mathrm{~min}$ at room temperature. The cells were then rinsed again with $60 \%$ isopropanol and incubated with fresh-filtered oil red $\mathrm{O}$ solution $(60 \%$ saturated oil red $\mathrm{O} / 40 \%$ deionized water) for $20 \mathrm{~min}$. For analysis, the slides were washed in isopropanol for $10 \mathrm{~min}$, rinsed in distilled water, counterstained with hematoxylin and mounted in glycerol/gelatin solution. Images of cells were captured using a fluorescence microscope.

Analysis of apoptosis by flow cytometry (FCM) of Annexin-V/ propidiumiodide (AV/PI) dual staining. The RAW264.7 cells were incubated with ox-LDL of designed concentrations and were then processed with an AV-FITC kit (Keygene, KGA108) according to the manufacturer's instructions. The samples were analyzed by FACScan flow cytometer (Becton-Dickinson, Franklin
Lakes, NJ, USA) in order to quantify the apoptotic rate. Different subpopulations were distinguishable: Q1, Annexin V-negative but PI-positive, i.e., necrotic cells; Q2, Annexin V/PI-double positive, i.e., late apoptotic cells; Q3, Annexin V/PI-double negative, i.e., live cells; Q4, Annexin V-positive but PI-negative, i.e., early apoptotic cells. The apoptotic rate was determined as the percentage of Q2 + Q4.

Detection of autophagosomes by TEM analysis. The treated cells were rinsed with ice-cold PBS and centrifuged at $1,000 \mathrm{x} \mathrm{g}$ for $5 \mathrm{~min}$ at room temperature, after which the clear supernatants were removed. Cell pellets were fixed with $2.5 \%$ glutaraldehyde in $0.1 \mathrm{M}$ cacodylate buffer, $\mathrm{pH} 7.4$ for at least $30 \mathrm{~min}$ at $4^{\circ} \mathrm{C}$. After fixation, the specimens were thoroughly washed in $0.1 \mathrm{M}$ cacodylate buffer and then post-fixed with $1 \%$ osmium tetroxide in the same buffer for $1 \mathrm{~h}$ at room temperature. The specimens were dehydrated in a graded series of ethanol, and embedded in Epon, then $0.1 \mu \mathrm{m}$ thin sections were stained with uranylacetate/lead citrate and viewed in a Hitachi H-300 TEM.

Measurement of the efferocytosis of apoptotic RAW264.7 cells. The measurement of the efferocytosis of RAW264.7 cells was performed as described by Li et al, Yancey et al and Jehle et al (48-50). The RAW264.7 cells were made apoptotic by incubation with ox-LDL followed by treatments in the aforementioned 6 groups. After vigorous washing with PBS, the cells were fixed in $4 \%$ paraformaldehyde and counterstained with PI. The cells in 6 groups were incubated for $2 \mathrm{~h}$ with fresh RAW264.7 cells which were labeled with CFSE cell tracer. The efferocytosis of apoptotic RAW264.7 cells was visualized using fluorescence microscopy. PI red-labeled apoptotic RAW264.7 cells merged into CFSE cell tracer green-labeled fresh RAW264.7 cells, which was considered as phagocytosis of the apoptotic cells by fresh RAW264.7 cells. The phagocytic index was used to evaluate the efferocytosis of apoptotic RAW264.7 cells. The phagocytic index was calculated using the formula: Phagocytic index = (number of phagocytized RAW264.7 cells/number of total cells) x 100. Experiments were repeated five times and the analysis was performed in a blinded fashion by two independent observers.

Statistical analysis. Data are expressed as mean \pm SD. Statistical analysis of data was performed by applying the Student's t-test to determine the significance between two groups. Statistical significance of pairwise differences among three or more groups were determined using one-way analysis of variance (ANOVA) followed by post-hoc test. $\mathrm{P}<0.05$ was considered statistically significant. Analysis was performed using SPSS for Windows (SPSS Inc., Version 16.0, Chicago, IL, USA).

\section{Results}

Expression of Sirt1 and autophagy marker proteins was elevated at optimal concentrations and time point of $o x-L D L$. The effects of ox-LDL $(25,50$ and $100 \mu \mathrm{M})$ on the expression of Sirt1 and autophagy marker proteins at different time points $(12,24$ and $48 \mathrm{~h})$ were examined. Our results showed that ox-LDL of appropriate concentration elevated the levels of Sirt1 and autophagy marker proteins such as Atg5, Atg7 and LC3-II/LC3-I at optimal time points. 
A
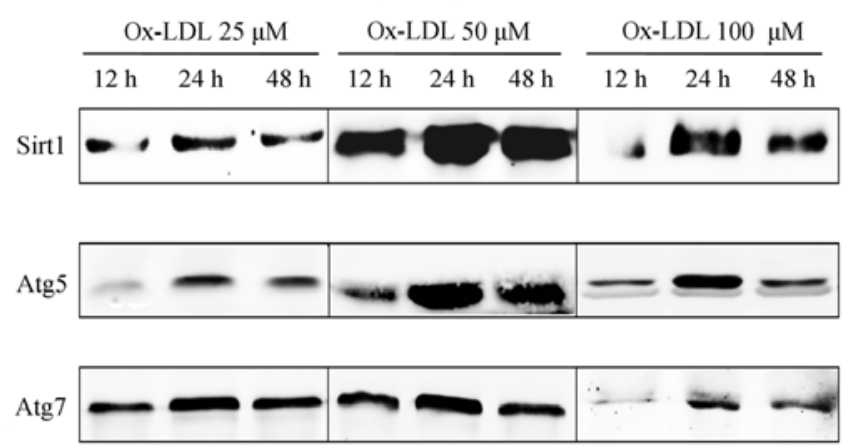

LC3-I

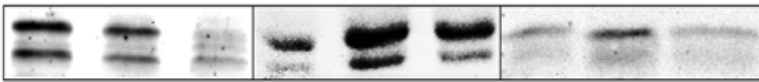

$\beta$-actin

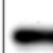

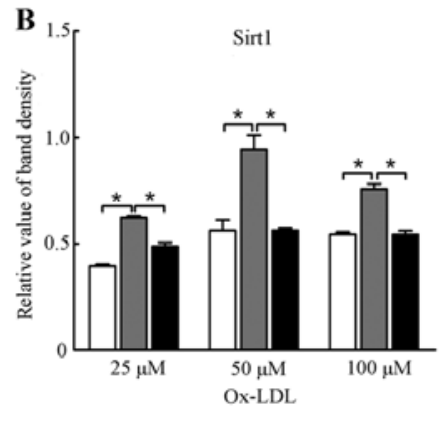
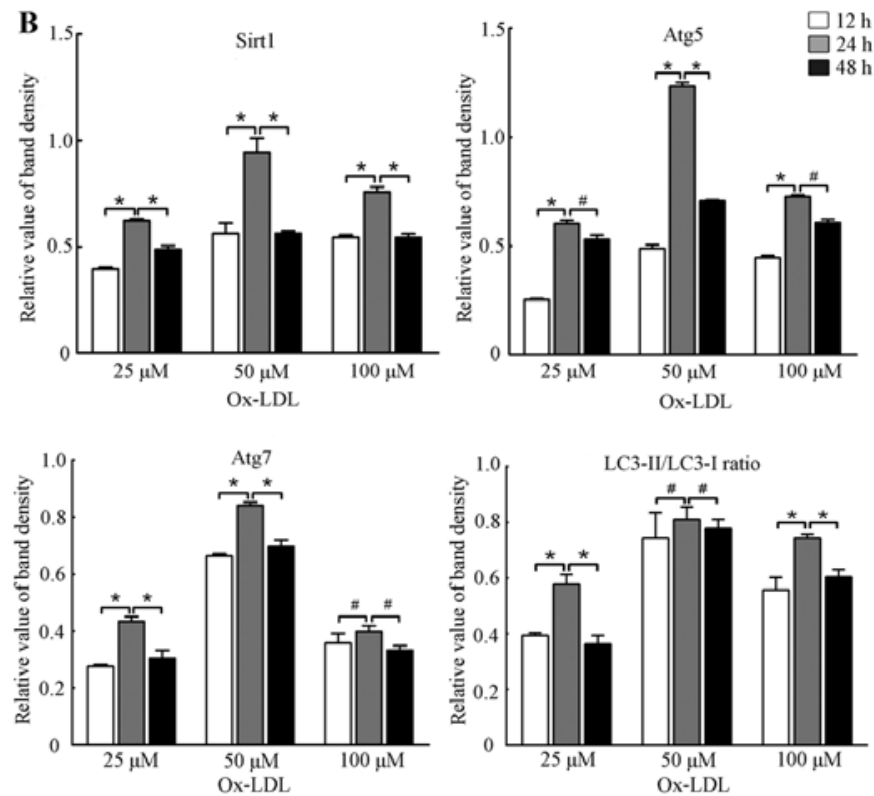

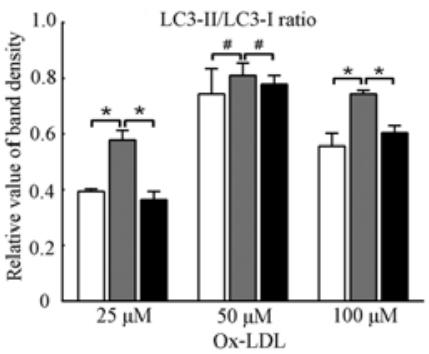

Figure 1. Expression of Sirtuin1 (Sirt1) and autophagy marker proteins in RAW264.7 cells treated with ox-LDL at different concentrations and time points. (A) Representative results of assays of Sirt1, Atg5, Atg7, LC3-I and LC3-II and $\beta$-actin abundances in RAW264.7 cells with ox-LDL of designated concentrations $(25,50$ and $100 \mu \mathrm{M})$ and time points (12,24 and $48 \mathrm{~h})$ using western blot analysis. (B) Protein expression levels of Sirt1 were analyzed by western blotting by using polyclonal antibodies to Sirt1, Atg5, Atg7, LC3-I and LC3-II, respectively, in order to quantify the expression in RAW264.7 cells. LC3-II/LC3-I ratio was calculated. $\beta$-actin was used as an equal loading control. The band value was quantified by densitometric analysis. The expression of all the proteins was increased most at $24 \mathrm{~h}$ compared with 12 or $48 \mathrm{~h}$ (all $\mathrm{P}<0.05)$. Experiments were repeated at least three times. Data are expressed as the mean $\pm \mathrm{SD}$ in the corresponding bar graph and statistical significance was determined by the Student's t-test. Columns, mean; error bars, $\pm \mathrm{SD} ;{ }^{*} \mathrm{P}<0.05$, ${ }^{*} \mathrm{P}<0.01$.

A

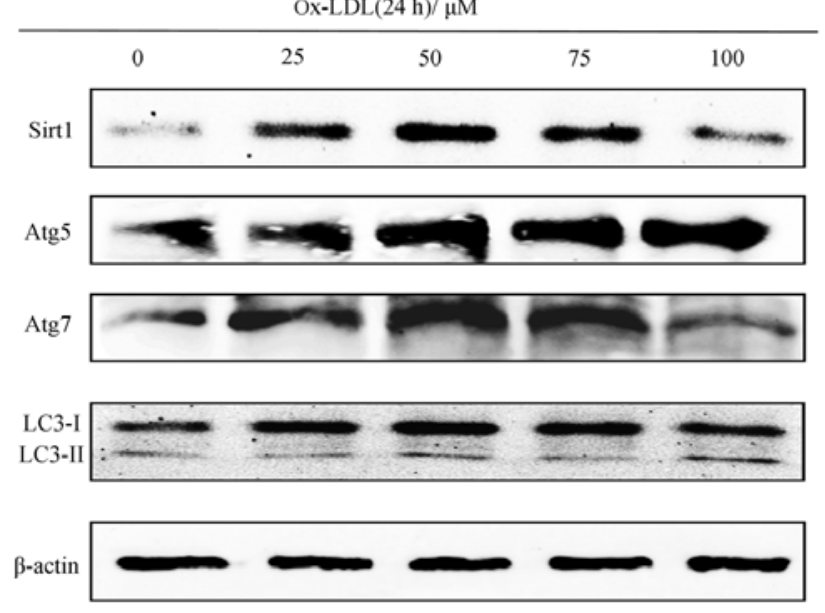

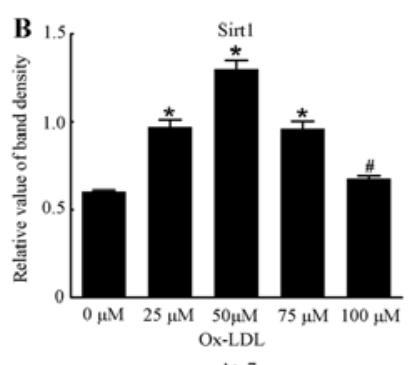
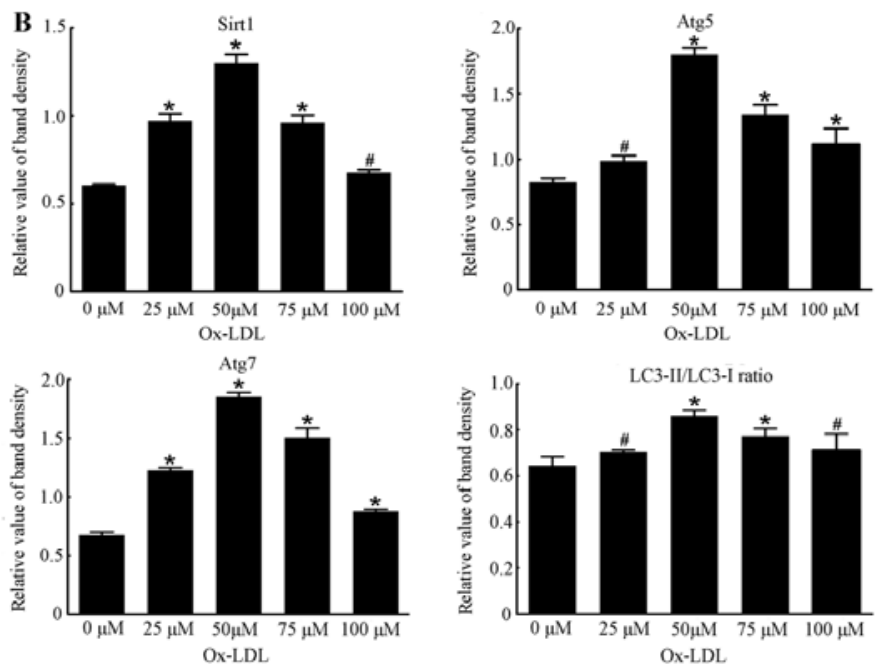

Figure 2. The optimal concentration of ox-LDL for the expression of Sirtuin1 (Sirt1) and autophagy marker proteins in RAW264.7 cells after incubation for $24 \mathrm{~h}$. (A) Representative western blot analysis results of Sirt1, Atg5, Atg7, LC3-I and LC3-II and $\beta$-actin abundances in RAW264.7 cells following stimulation with different concentrations of ox-LDL $(0,25,50,75$ and $100 \mu \mathrm{M})$ for $24 \mathrm{~h}$. (B) Protein levels of Sirt1, Atg5, Atg7, LC3-I and LC3-II were analyzed by western blotting in RAW264.7 cells, respectively. The LC3-II/LC3-I ratio was calculated. $\beta$-actin was used as an equal loading control. The band value was quantified by densitometric analysis. The expression of all the proteins was increased after incubation with ox-LDL at the designated concentrations compared with $0 \mu \mathrm{M}$ ox-LDL (all $\mathrm{P}<0.05$ ). The optimal concentration of ox-LDL was $75 \mu \mathrm{M}$ compared with the other groups. Experiments were repeated at least three times. Data are expressed as the mean \pm SD in the corresponding bar graph and statistical significance was determined by the Student's t-test. Columns, mean; error bars, $\pm \mathrm{SD} ;{ }^{*} \mathrm{P}<0.05$ vs. $0 \mu \mathrm{M}$ group, ${ }^{*} \mathrm{P}<0.01$ vs. $0 \mu \mathrm{M}$ group.

Results of the western blot analysis shown in Figs. 1 and 2 revealed that the expression of Sirt1 and autophagy marker proteins was increased at $24 \mathrm{~h}$ (all $\mathrm{P}<0.05 \mathrm{vs} .12 \mathrm{~h}$ ), and then decreased at $48 \mathrm{~h}$ (all $\mathrm{P}<0.05$ vs. $24 \mathrm{~h}$ ). The expression of Sirtl and autophagy marker proteins was significantly higher at $50 \mu \mathrm{M}$ ox-LDL (all $\mathrm{P}<0.05$ vs. $0 \mu \mathrm{M}$ ), but was reduced when the cells were treated with 75 and $100 \mu \mathrm{M}$ ox-LDL (all
$\mathrm{P}<0.05$ vs. $0 \mu \mathrm{M})$. Thus, cells treated with $50 \mu \mathrm{M}$ ox-LDL for $24 \mathrm{~h}$ may be considered optimal for the expression of Sirt1 and autophagy marker proteins. Moreover, the results suggested that autophagy was induced concomitantly with the induction of expression of Sirtl by a moderate stimulus of ox-LDL, suggesting that Sirt1 is involved in autophagy under treatment of ox-LDL to some extent. 


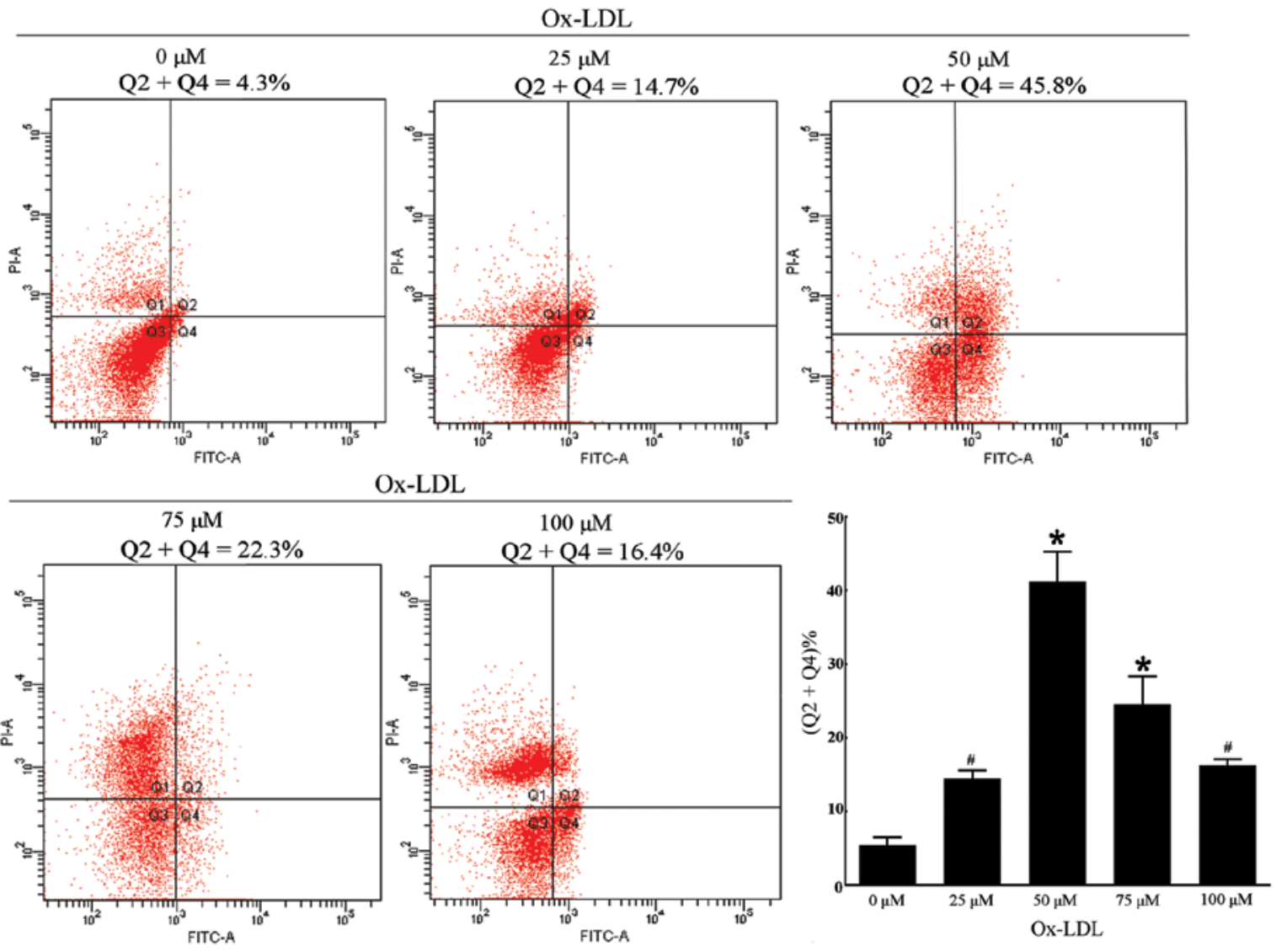

Figure 3. Quantitative analysis of apoptosis by flow cytometry (FCM) of Annexin-V/propidium iodide (AV/PI) dual staining in ox-LDL-treated RAW264.7 cells. The cells were treated with different concentrations of ox-LDL $(0,25,50,75$ and $100 \mu \mathrm{M})$ for $2 \mathrm{~h}$. The results showed that the apoptotic rates were all increased after treatment with ox-LDL at the designated concentrations (all $\mathrm{P}<0.05 \mathrm{vs}$.), but increased most in the $50 \mu \mathrm{M}$ group (P<0.001 vs. $0 \mu \mathrm{M}$ group). Experiments were repeated three times. Data are expressed as the mean \pm SD in the corresponding bar graph and statistical significance was determined by Student's t-test. Columns, mean; error bars, $\pm \mathrm{SD} ;{ }^{*} \mathrm{P}<0.05$ vs. $0 \mu \mathrm{M}$ group, ${ }^{*} \mathrm{P}<0.01$ vs. $0 \mu \mathrm{M}$ group.

Ox-LDL treatment simultaneously induces autophagy and apoptosis in RAW264.7 cells. We investigated cell apoptosis when the cells were incubated with different concentrations of ox-LDL for $24 \mathrm{~h}$. An appropriate concentration of ox-LDL for further measurement of efferocytosis was required according to the apoptotic rate. Additionally, the quantitative analysis of apoptosis by FCM of AV/PI dual staining at designated concentrations showed that the apoptotic rate increased at $25 \mu \mathrm{M}(14.52 \pm 1.08 \%$ vs. $0 \mu \mathrm{M}, 5.43 \pm 1.04 \%)$ and $50 \mu \mathrm{M}$ $(41.23 \pm 4.02 \%)$ in a dose-dependent manner and markedly accelerated when treated with $50 \mu \mathrm{M}$ ox-LDL (Fig. 3). The apoptotic rate decreased when the cells were incubated with $75 \mu \mathrm{M}(24.53 \pm 3.82 \%)$ and $100 \mu \mathrm{M}(16.30 \pm 0.79 \%)$ ox-LDL. By comparing the apoptotic rate among these concentrations, the data suggested that the apoptotic rate was appropriate when the cells were treated with $50 \mu \mathrm{M}$ ox-LDL ( $<<0.001 \mathrm{vs}$. $0 \mu \mathrm{M})$. Furthermore, the previous results showed that, cells treated with $50 \mu \mathrm{M}$ ox-LDL for $24 \mathrm{~h}$ would be optimal for the expression of autophagy marker proteins, which is similar to the condition of cell apoptosis. The evidence suggested that autophagy and apoptosis of RAW264.7 cells were triggered by incubation with $50 \mu \mathrm{M}$ ox-LDL for $24 \mathrm{~h}$.

Different doses of RSV and NAM exert dual effects on cell proliferation and the expression of Sirtl in RAW264.7 cells. Low concentration RSV exerted a protective effect on cells.
However, high concentration RSV may induce cell necrosis and apoptosis of RAW264.7 cells (51). NAM of different concentrations was also able to promote or inhibit cell proliferation $(52,53)$. The dual effects of RSV and NAM on cell proliferation and the expression of Sirt1 in RAW264.7 cells were examined. The appropriate high and low concentrations of RSV or NAM for cell proliferation, respectively, were identified. The results of CCK-8 assay indicated that the cell proliferation rates increased significantly when incubated with $12.5 \mu \mathrm{M}$ RSV $(0.69 \pm 0.01 \mathrm{OD})$, compared with that of the $0 \mu \mathrm{M}$ group $(0.45 \pm 0.03 \mathrm{OD}), 5 \mu \mathrm{M}$ group $(0.49 \pm 0.02 \mathrm{OD})$, $25 \mu \mathrm{M}$ group $(0.62 \pm 0.02 \mathrm{OD}), 50 \mu \mathrm{M}$ group $(0.61 \pm 0.04 \mathrm{OD})$ and $100 \mu \mathrm{M}$ group $(0.34 \pm 0.01 \mathrm{OD})$. The proliferation rates decreased significantly when the cells incubated with $100 \mu \mathrm{M}$ RSV (0.34 \pm 0.01 OD vs. $50 \mu \mathrm{M}: 0.61 \pm 0.04$ OD) (Fig. 4A). Similarly, the cell proliferation rates remained appropriate when incubated with $5 \mathrm{mM}$ NAM $(0.52 \pm 0.03$ OD) compared with $0 \mathrm{mM}$ NAM $(0.52 \pm 0.04 \mathrm{OD})$. The proliferation rates decreased in the $10 \mathrm{mM}$ NAM group $(0.41 \pm 0.02 \mathrm{OD}), 20 \mathrm{mM}$ NAM group $(0.40 \pm 0.02 \mathrm{OD})$, and most significantly, the $40 \mathrm{mM}$ NAM $(0.25 \pm 0.03 \mathrm{OD})$ and $80 \mathrm{mM}$ NAM groups $(0.14 \pm 0.02$ OD) (Fig. 4B). These results suggested that the cell status was extremely poor when incubated with $100 \mu \mathrm{M}$ RSV, 40 and $80 \mathrm{mM}$ NAM. Thus, the high and low concentrations of RSV were 50 and $12.5 \mu \mathrm{M}$, while the corresponding high and low concentrations of NAM were 20 and $5 \mathrm{mM}$. Furthermore, 
A

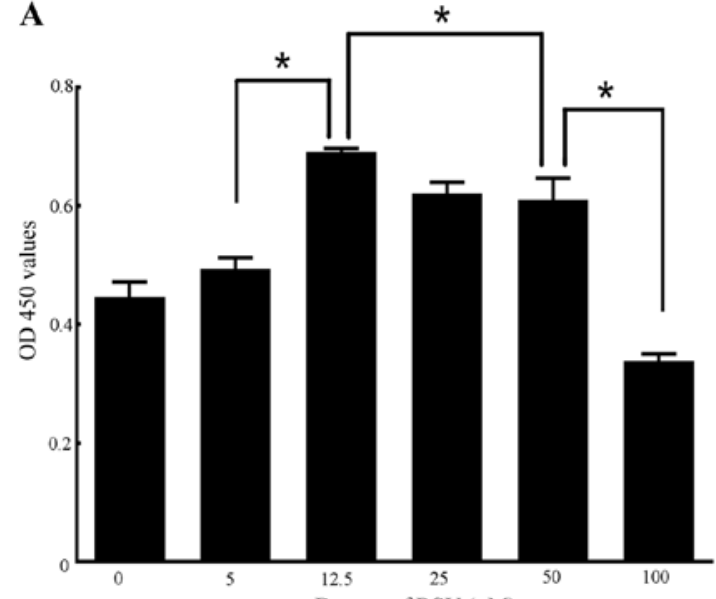

B

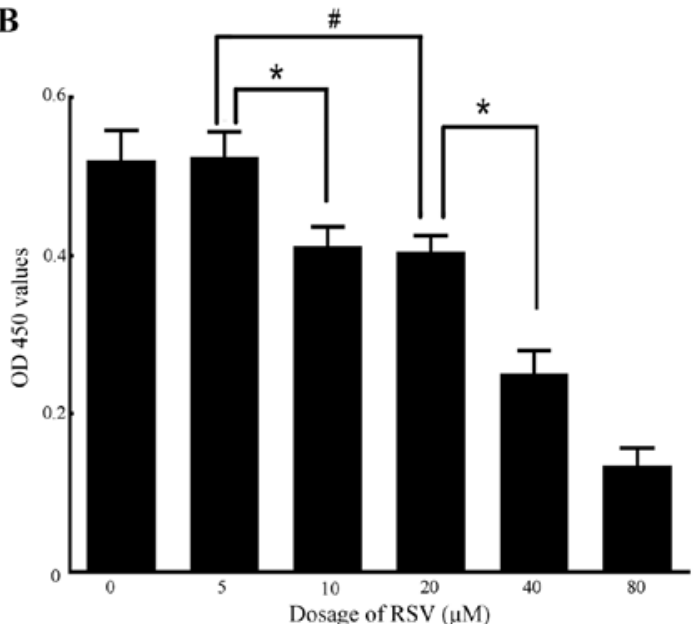

Figure 4. Determination of high and low concentrations of resveratrol (RSV) or nicotinamide (NAM) by analysis of cell proliferation rates using the Cell Counting Kit-8 (CCK-8) assay. (A) Results of CCK-8 assay on RAW264.7 cells incubated with different doses of RSV (0, 5, 12.5, 25, 50 and $100 \mu \mathrm{M})$. No significant differences were observed in comparisons between 0 and $5 \mu \mathrm{M}$, and 25 and $50 \mu \mathrm{M}$ groups, respectively. A significant difference was observed between the 5 and $12.5 \mu \mathrm{M}, 12.5$ and $50 \mu \mathrm{M}$ group, and 50 and $100 \mu \mathrm{M}$ groups, respectively (all $\mathrm{P}<0.01$ ). (B) Results of CCK-8 assay on RAW264.7 cells incubated with different doses of NAM $(0,5,10,20,40$ and $80 \mathrm{mM})$. No significant differences were shown in comparisons between the 0 and $5 \mathrm{mM}$, and 10 and $20 \mathrm{mM}$ groups, respectively. A significant difference was observed between the 5 and $10 \mathrm{mM}, 5$ and $20 \mathrm{mM}$, and 20 and $40 \mathrm{mM}$ groups, respectively (all $\mathrm{P}<0.05$ ). Experiments were repeated three times. Data are expressed as the mean $\pm \mathrm{SD}$ in the corresponding bar graph and statistical significance was determined by the Student's t-test. Columns, mean; error bars, $\pm \mathrm{SD} ;{ }^{*} \mathrm{P}<0.05,{ }^{*} \mathrm{P}<0.01$.

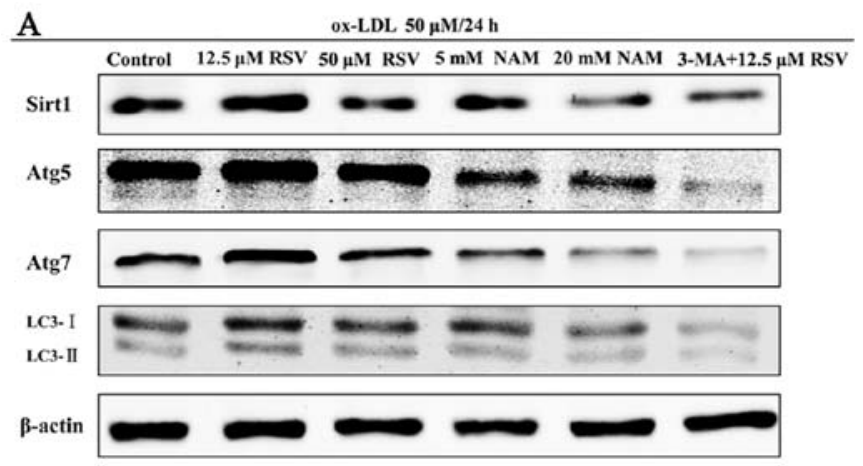

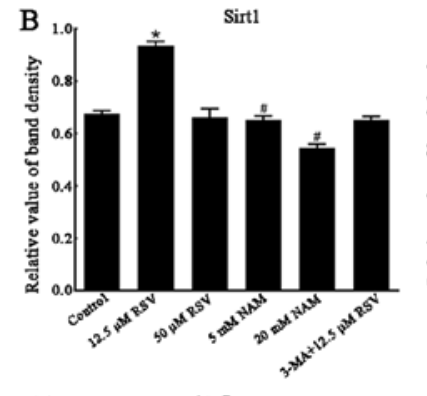

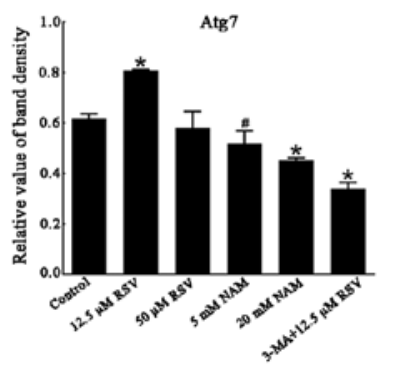

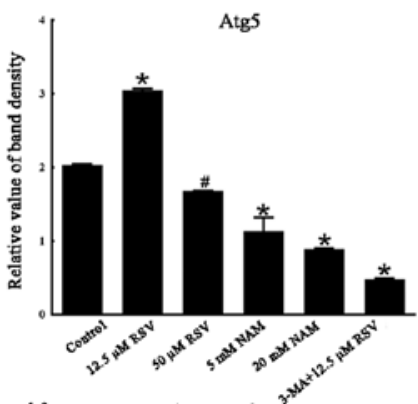

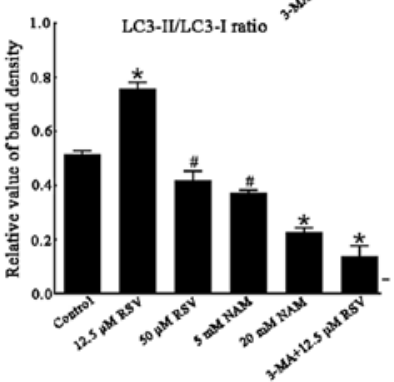

Figure 5. Expression of Sirtuin1 (Sirt1) and autophagy marker proteins in ox-LDL-induced apoptotic RAW264.7 cells of different treatments. The apoptotic cells were randomly divided into 6 groups: i) control, ii) $12.5 \mu \mathrm{M}$ resveratrol (RSV), iii) $50 \mu \mathrm{M}$ RSV, iv) 5 mM nicotinamide (NAM), v) $20 \mathrm{mM}$ NAM, vi) 3-methyladenine (3-MA) $+12.5 \mu \mathrm{M}$ RSV. (A) Representative results of assays of Sirt1, Atg5, Atg7, LC3-I, LC3-II and $\beta$-actin abundances of 6 groups using western blot analysis. (B) The levels of Sirt1, Atg5, Atg7, LC3-I and LC3-II protein expression were analyzed by western blot analysis by using polyclonal antibodies to Sirt1, Atg5, Atg7, LC3-I and LC3-II to quantify the expression in these groups. LC3-II/LC3-I ratio was calculated. Sirt1 expression was significantly elevated in $12.5 \mu \mathrm{M}$ RSV group, compared with control group $(\mathrm{P}=0.002)$. No statistical significance was observed between the 3-MA $+12.5 \mu \mathrm{M}$ RSV and control groups following inhibition of autophagy. The levels of all autophagy marker proteins were significantly increased in $12.5 \mu \mathrm{M}$ RSV group simultaneously, compared with the control group (all $\mathrm{P}<0.05$ ). $\beta$-actin was used as an equal loading control. The band value was quantified by densitometric analysis. Experiments were repeated at least three times. Data are expressed as the mean \pm SD in the corresponding bar graph and statistical significance was determined by the Student's t-test. Columns, mean; error bars, $\pm \mathrm{SD} ;{ }^{*} \mathrm{P}<0.05$ vs. control group, ${ }^{*} \mathrm{P}<0.01$ vs. control group.

after the RAW264.7 cells were made apoptotic, the results of western blotting revealed that Sirt1 expression was increased when cells were incubated with $12.5 \mu \mathrm{M}$ RSV and $5 \mathrm{mM}$ NAM compared with that of $50 \mu \mathrm{M}$ RSV and $20 \mathrm{mM}$ NAM, respectively (both $\mathrm{P}<0.05$ vs. control) (Fig. $5 \mathrm{~A}$ and $\mathrm{B}$ ).
Sirtl possibly contributes to autophagy in apoptotic $R A W 264.7$ cells following treatment of ox- $L D L$. To define the potential role of Sirt1 in autophagy, we examined the expression of Sirt1 and autophagy marker proteins in apoptotic RAW264.7 cells following the treatment of $50 \mu \mathrm{M}$ ox-LDL 

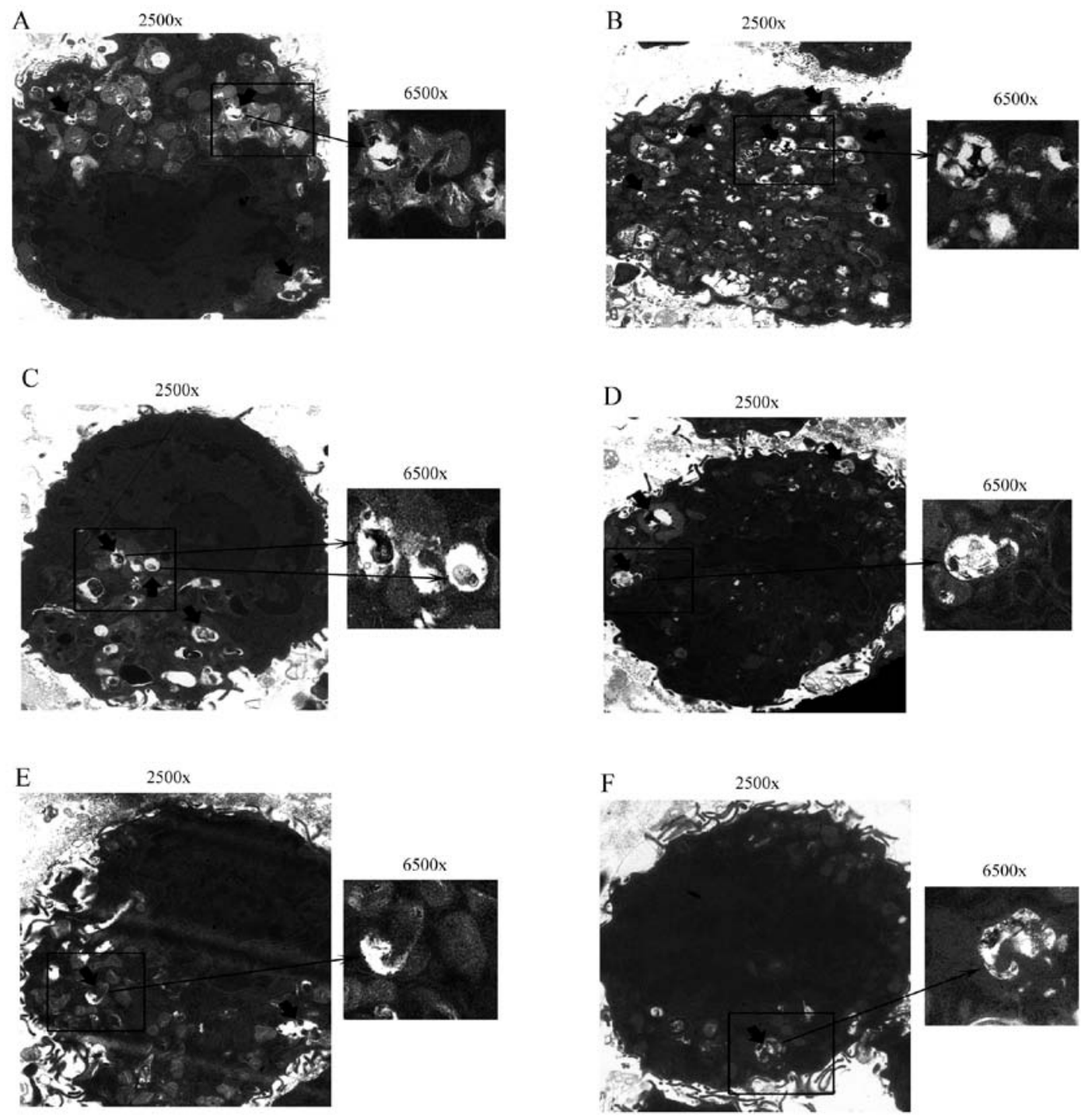

Figure 6. Representative results of the formation and structure of autophagosomes in ox-LDL-induced apoptotic RAW264.7 cells of different treatments. The autophagosomes were detected by TEM. (A) Control group, (B) $12.5 \mu \mathrm{M}$ resveratrol (RSV) group, (C) $50 \mu \mathrm{M}$ RSV group, (D) $5 \mathrm{mM}$ nicotinamide (NAM) group, (E) $20 \mathrm{mM}$ NAM group and (F) 3-methyladenine (3-MA) + $12.5 \mu \mathrm{M}$ RSV group. The formation of autophagosomes was detected in each group However, there were significantly more autophagosomes in the $12.5 \mu \mathrm{M}$ RSV group. Inhibition of autophagy resulted in a significant reduction of autophagosomes in the 3-MA + 12.5 $\mu \mathrm{M}$ RSV group. Experiments were repeated five times. Black arrow, autophagosome.

for $24 \mathrm{~h}$, using high and low concentration RSV or NAM. We also investigated the expression of these proteins when the cells were incubated with 3-MA, the chemical inhibitor of autophagy. Treatment with $12.5 \mu \mathrm{M}$ RSV significantly increased the expression of autophagy marker proteins such as Atg5, Atg7 and LC3-II/LC3-I, which was accompanied by the activation of Sirt1 (all $\mathrm{P}<0.05$ vs. control group). The expression of Sirt1 and autophagy marker proteins in the 5 and $20 \mathrm{mM}$ NAM groups were simultaneously decreased as compared to the control group (all $\mathrm{P}<0.05$ ) (Fig. 5). Moreover, the expression of Sirt1 in the 3-MA $+12.5 \mu \mathrm{M}$ RSV group showed no significant difference compared with the control group $(\mathrm{P}=0.07)$ subsequent to inhibition of autophagy (Fig. 5A and B). We also detected the autophagosomes of these groups via TEM analysis. Significantly more autophagosomes were identified in the $12.5 \mu \mathrm{M}$ RSV group compared with the other groups, while there was hardly any formation of autophagosomes in the $3-\mathrm{MA}+12.5 \mu \mathrm{M}$ RSV group
(Fig. 6). These results showed that Sirtl was able to regulate the expression of autophagy marker proteins in RAW264.7 cells.

Upregulation of autophagy enhanced efferocytosis of apoptotic RAW264.7 cells. The relationship between Sir1-mediated autophagy and efferocytosis in apoptotic RAW264.7 cells was investigated. ox-LDL uptake was detected, which may be useful in the elevation of the phagocytosis of RAW264.7 cells regulated by Sirt1 and autophagy. As determined by oil red $\mathrm{O}$ staining (Fig. 7), ox-LDL uptake in the 12.5 and $50 \mu \mathrm{M}$ RSV groups were decreased compared with the control group $(\mathrm{P}<0.001, \mathrm{P}=0.008$ respectively), which was accompanied by the upregulation of autophagy. By contrast, ox-LDL uptake in the $20 \mathrm{mM}$ group NAM showed a significant increase ( $\mathrm{P}=0.03$ vs. control group), whereas a decrease was identified in the $3-\mathrm{MA}+12.5 \mu \mathrm{M}$ RSV group following the inhibition of autophagy $(\mathrm{P}<0.001$ vs. control group). This finding may 
A

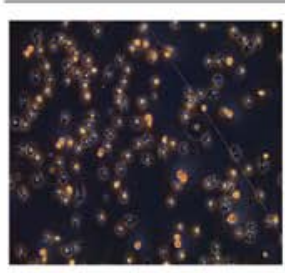

Control

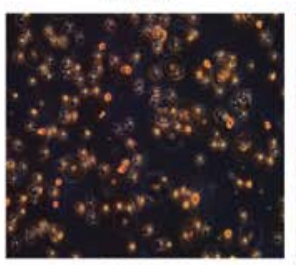

$5 \mathrm{mMNAM}$
Ox-LDL $50 \mu \mathrm{M} / 24 \mathrm{~h}$

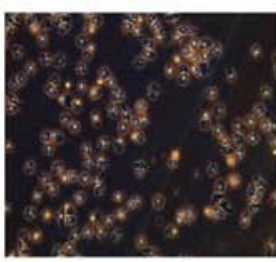

$12.5 \mu \mathrm{M}$ RSV

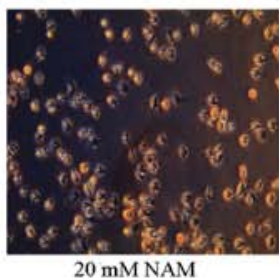

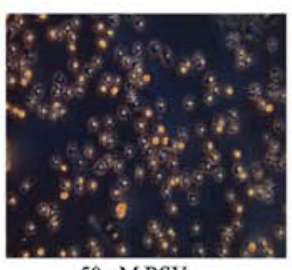

$50 \mu \mathrm{M}$ RSV

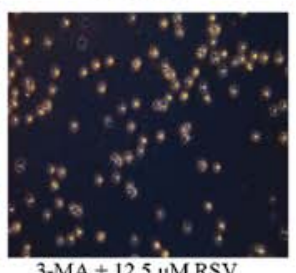

3-MA+ $12.5 \mu \mathrm{M}$ RSV
B

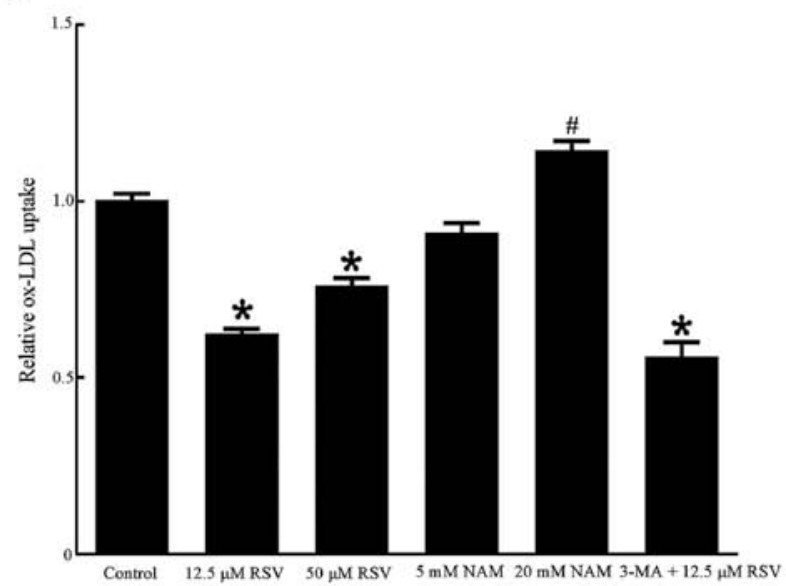

Figure 7. The ox-LDL uptake of apoptotic RAW264.7 cells of different treatments. (A) Representative results of oil red O staining in ox-LDL-induced apoptotic RAW264.7 cells of different treatments. Images were obtained from a fluorescence microscope. Red fluorescence represents the accumulation of ox-LDL in cells. (B) Analysis of ox-LDL uptake in apoptotic RAW264.7 cells of different treatments. Results were shown as fold changes in the proportions of the oil red O-stained positive area compared with the control. The ox-LDL uptake in the 12.5 and $50 \mu \mathrm{M}$ resveratrol (RSV) group was decreased ( $\mathrm{P}<0.001, \mathrm{P}=0.008$ vs. control group respectively), and increased in the $20 \mathrm{mM}$ group ( $\mathrm{P}=0.03$ vs. control group). The ox-LDL uptake was also decreased in the 3-methyladenine (3-MA) + 12.5 $\mu$ M RSV group compared with the control group $(\mathrm{P}<0.001)$, which was possibly caused by elevation in the level of Sirtuin1 (Sirt1) although the autophagy was inhibited. Experiments were repeated five times. Data are expressed as the mean \pm SD in the corresponding bar graph and statistical significance was determined by the Student's t-test. Columns, mean; error bars, $\pm \mathrm{SD} ;{ }^{*} \mathrm{P}<0.05$ vs. control group, ${ }^{*} \mathrm{P}<0.01$ vs. control group.

$\mathbf{A}$

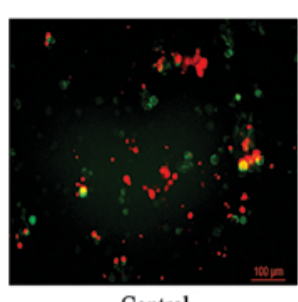

Control

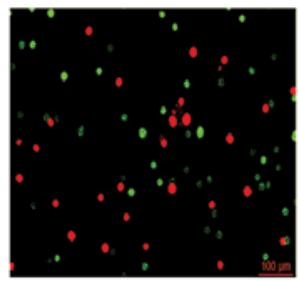

5 mM NAM
Ox-LDL $50 \mu \mathrm{M} / 24 \mathrm{~h}$

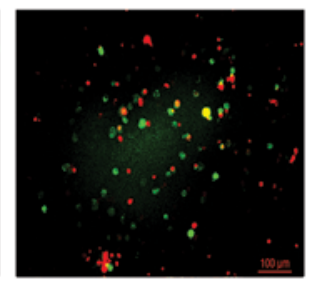

$12.5 \mu \mathrm{M}$ RSV

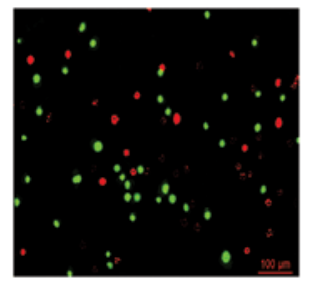

$20 \mathrm{mM}$ NAM

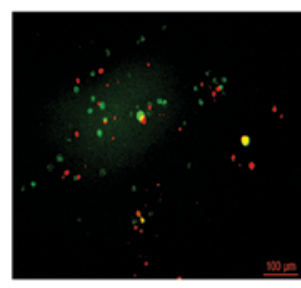

$50 \mu \mathrm{M}$ RSV

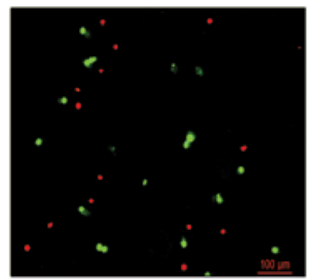

3-MA + $12.5 \mu \mathrm{M}$ RSV
B

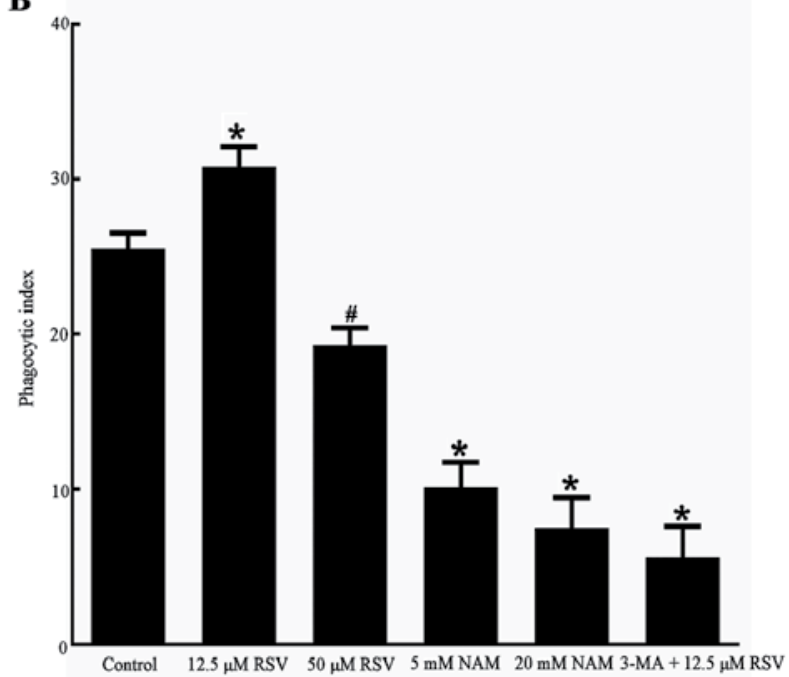

Figure 8. Measurement of the efferocytosis of ox-LDL-induced apoptotic RAW264.7 cells of different treatments. (A) Representative results of the efferocytosis of ox-LDL-induced apoptotic cells of different treatments. Images were obtained from a fluorescence microscope. Red fluorescence represents ox-LDL-induced apoptotic RAW264.7 cells using a PI staining. Green CFSE staining fluorescence represents fresh RAW264.7 cells. (B) Analysis of phagocytic index in apoptotic RAW264.7 cells of different treatments. The phagocytic index $12.5 \mu \mathrm{M}$ resveratrol (RSV) group was markedly increased compared with the control group $(\mathrm{P}<0.001)$, indicating that efferocytosis of apoptotic RAW264.7 cells was enhanced by Sirt1-mediated autophagy. The efferocytosis of apoptotic RAW264.7 cells was decreased in the $5 \mathrm{mM}$ nicotinamide (NAM), $20 \mathrm{mM} \mathrm{NAM}$ and 3-MA + $12.5 \mu \mathrm{M}$ RSV groups (all P<0.001 vs. control group). Data are expressed as the mean $\pm \mathrm{SD}$ in the corresponding bar graph and statistical significance was determined by the Student's t-test. Experiments were repeated five times. Columns, mean; error bars, $\pm \mathrm{SD}$; ${ }^{\#} \mathrm{P}<0.05$ vs. control group, ${ }^{*} \mathrm{P}<0.01$ vs. control group.

be attributed to the expression of Sirt1 since Sirt1 has been reported to decrease ox-LDL uptake and prevent macrophage foam cell formation through suppression of the expression of the scavenger receptor Lox-1 in macrophages (54). Another possible reason is the poor status of the cells in this group, since there were significant fewer cells compared with the other groups, as noted in the images obtained via fluorescence microscopy (Figs. 7A and 8A). The results from the measure- ment of the efferocytosis demonstrated that $12.5 \mu \mathrm{M}$ RSV caused a marked increase in the efferocytosis of apoptotic RAW264.7 cells compared with the control group $(\mathrm{P}<0.001)$ (Fig. 8), suggesting that upregulation of autophagy contributes to the phagocytic clearance of apoptotic cells. Similarly, the efferocytosis of apoptotic RAW264.7 cells was decreased in the 5 and 20 mM NAM groups $(\mathrm{P}=0.001, \mathrm{P}<0.001$ respectively vs. the control group). It is also likely that inhibition of autophagy 
by 3-MA contributes to defective efferocytosis, although Sirt1 was expressed. All our results showed that upregulation of autophagy was capable of enhancing efferocytosis of apoptotic RAW264.7 cells. Since the expression of Sirt1 was able to regulate autophagy and the improvement of efferocytosis was accompanied by an increase in the expression of Sirt1, the enhancement in efferocytosis of apoptotic RAW264.7 cells could be Sirt1-mediated. However, only the expression of Sirt1 did not induce enhancement in efferocytosis following inhibition of autophagy.

\section{Discussion}

The main aim of this study was to determine whether the upregulation of autophagy mediated by Sirt1 could enhance efferocytosis of apoptotic macrophages induced by ox-LDL. The expression of Sirt1 and autophagy marker proteins was investigated, using Sirt1 activator RSV and inhibitor NAM. The findings in our study suggest that with the increase in the expression of Sirtl activated by an appropriate dose of RSV, the expression of autophagy marker proteins was also increased. Furthermore, the efferocytosis of apoptotic RAW264.7 cells was also improved simultaneously with this increase.

Previous studies (13-16) have shown that macrophage autophagy in atherosclerosis becomes dysfunctional in atherosclerosis and its deficiency promotes vascular inflammation, oxidative stress, and plaque necrosis, suggesting a mechanismbased strategy to therapeutically suppress atherosclerosis progression. It is difficult to determine whether the vacuoles in their cytoplasm result from autophagocytosis or heterophagocytosis through conventional electron microscopy analysis. In addition, LC3 is poorly expressed in macrophages and overexpression of other lysosomal marker proteins may give rise to false-positive signals in immunoelectron microscopy $(23,24)$. Notably, pharmacological modulation of macrophage autophagy has been shown to affect vascular inflammation. Stent-based delivery of everolimus (a well-known autophagy inducer) in atherosclerotic plaques of high-fat diet-fed rabbits leads to a marked reduction of macrophages via autophagic cell death without altering the VSMC plaque content (13). Two recent studies have provided new dimensions to the understanding of the role of macrophage autophagy in regulating atherosclerosis. Razani and colleagues (15) demonstrated that initially autophagy is functional and becomes severely compromised with disease progression. This deficiency of macrophage autophagy may induce inflammosome hyperactivation through lysosomal leakage, generation of reactive oxygen species (ROS), and impaired mitophagy, thus increased vascular inflammation and plaque formation in apoE ${ }^{-/}$mice. Findings of another study provided evidence that inhibition of macrophage autophagy enhanced apoptosis and riphosphopyridine nucleotide (NADPH) oxidase-mediated oxidative stress, rendering the apoptotic cells less recognizable to efferocytosis in low-density lipoprotein receptor (LDLr) ${ }^{-1-}$ mice (16). The defective efferocytosis could promote plaque necrosis in advanced atherosclerosis. These data indicated a protective role played by macrophage autophagy in the two most widely used mouse models of atherosclerosis.

Sirt1 has been recently regarded as a new factor in the regulation of autophagy. The decrease in Sirtl protein expression may lead to inflammation through dysregulation of autophagy and increased levels of acetylated nuclear factor- $\kappa \mathrm{B}(\mathrm{NF}-\kappa \mathrm{B})(55,56)$. Sirt1 regulated autophagy by promoting the formation of autophagosome in a cellular model of oxidative stress (57). Moreover, RSV exerted protective effects on cells through the activation of the adenosine 5'-monophosphate-activated protein kinase (AMPK)-SIRT1-autophagy pathway. Inhibition of Sirt1 contributes to the dysregulation of other nutrient-sensing pathways including mammalian target of rapamycin (mTOR) and AMPK, thereby leading to the impairment of autophagy in human macrophage, which may induce inflammation through $\mathrm{NF}-\kappa \mathrm{B}$ activation and the accumulation of autophagy marker proteins $(58,59)$. However, few studies have explored the relationship between efferocytosis of apoptotic macrophage cells and autophagy mediated by Sirt1. Our results mainly provide preliminary evidence that Sirt1 potentially affects the efferocytosis of apoptotic macrophages via the activation of autophagy, which is useful in understanding the molecular mechanism and pathogenesis of atherosclerosis. Our findings may have implications regarding the influence of defective autophagy on cell survival and the expression of Sirt1 in atherosclerosis, since the cell status was poor and the level of Sirt1 was not elevated when the cells were incubated with 3-MA + $12.5 \mu \mathrm{M}$ RSV.

Limitations to our study should be noted. The study was performed using in vivo experimental systems. Additionally, the relationship between efferocytosis of apoptotic macrophages and Sirtl should be confirmed in the atherosclerotic plaques through in vitro experiments. We only detected the efferocytosis of apoptotic macrophages enhanced by Sirt1-mediated moderate autophagy. Thus, the effect of Sirt1mediated excessive autophagy on efferocytosis of apoptotic macrophages should also be determined. Studies are also required to elucidate the signaling pathways underlying this mechanism.

In conclusion, results of the present study showed that autophagy was upregulated by an appropriate dose of Sirt1 activator RSV, and that the efferocytosis of apoptotic RAW264.7 was significantly improved when incubated with the appropriate dose of RSV compared with Sirt1 inhibitor NAM and autophagy inhibitor 3-MA. This enhancement in efferocytosis may be associated with Sirt1-mediated autophagy.

\section{Ackowledgements}

This study was supported by National Natural Science Foundation of China (No. 81200198) and Shanghai Municipal Health Bureau research projects (Grant No. 20124224), P.R. China to Buchun Zhang. We completed this study at the Central Laboratory of the Shanghai Tenth People's Hospital of Tongji University. The authors would like to thank Jianhui Zhuang, Ke Wang and Hailing Li from Tongji University School of Medicine for their helpful discussions.

\section{References}

1. Gersh BJ, Sliwa K, Mayosi BM and Yusuf S: Novel therapeutic concepts: the epidemic of cardiovascular disease in the developing world: global implications. Eur Heart J 31: 642-648, 2010.

2. Moore KJ and Tabas I: Macrophages in the pathogenesis of atherosclerosis. Cell 145: 341-355, 2011. 
3. Gautier EL, Jakubzick C and Randolph GJ: Regulation of the migration and survival of monocyte subsets by chemokine receptors and its relevance to atherosclerosis. Arterioscler Thromb Vasc Biol 29: 1412-1418, 2009.

4. Gerrity RG: The role of the monocyte in atherogenesis: I. Transition of blood-borne monocytes into foam cells in fatty lesions. Am J Pathol 103: 181-190, 1981.

5. Swirski FK, Pittet MJ, Kircher MF, Aikawa E, Jaffer FA, Libby P and Weissleder R: Monocyte accumulation in mouse atherogenesis is progressive and proportional to extent of disease. Proc Natl Acad Sci USA 103: 10340-10345, 2006.

6. Ylä-Herttuala S, Palinski W, Rosenfeld ME, Parthasarathy S, Carew TE, Butler S, Witztum JL and Steinberg D: Evidence for the presence of oxidatively modified low density lipoprotein in atherosclerotic lesions of rabbit and man. J Clin Invest 84 1086-1095, 1989.

7. Colles SM, Maxson JM, Carlson SG and Chisolm GM: Oxidized LDL-induced injury and apoptosis in atherosclerosis. Potential roles for oxysterols. Trends Cardiovasc Med 11: 131-138, 2001.

8. Salvayre R, Auge N, Benoist H and Negre-Salvayre A: Oxidized low-density lipoprotein-induced apoptosis. Biochim Biophys Acta 1585: 213-221, 2002.

9. Napoli C: Oxidation of LDL, atherogenesis, and apoptosis. Ann NY Acad Sci 1010: 698-709, 2003.

10. Stoneman VE and Bennett MR: Role of apoptosis in atherosclerosis and its therapeutic implications. Clin Sci (Lond) 107: 343-354, 2004.

11. Tabas I: Apoptosis and efferocytosis in mouse models of atherosclerosis. Curr Drug Targets 8: 1288-1296, 2007.

12. Seimon T and Tabas I: Mechanisms and consequences of macrophage apoptosis in atherosclerosis. J Lipid Res 50: S382-S387, 2009

13. Verheye S, Martinet W, Kockx MM, Knaapen MW, Salu K, Timmermans JP, Ellis JT, Kilpatrick DL and De Meyer GR: Selective clearance of macrophages in atherosclerotic plaques by autophagy. J Am Coll Cardiol 49: 706-715, 2007.

14. De Meyer I, Martinet W, Schrijvers DM, Timmermans JP, Bult H and De Meyer GR: Toll-like receptor 7 stimulation by imiquimod induces macrophage autophagy and inflammation in atherosclerotic plaques. Basic Res Cardiol 107: 269, 2012.

15. Razani B, Feng C, Coleman T, Emanuel R, Wen H, Hwang S Ting JP, Virgin HW, Kastan MB and Semenkovich CF: Autophagy links inflammasomes to atherosclerotic progression. Cell Metab 15: 534-544, 2012.

16. Liao X, Sluimer JC, Wang Y, Subramanian M, Brown K, Pattison JS, Robbins J, Martinez J and Tabas I: Macrophage autophagy plays a protective role in advanced atherosclerosis. Cell Metab 15: 545-553, 2012

17. Axe EL, Walker SA, Manifava M, Chandra P, Roderick HL, Habermann A, Griffiths G and Ktistakis NT: Autophagosome formation from membrane compartments enriched in phosphatidylinositol 3-phosphate and dynamically connected to the endoplasmic reticulum. J Cell Biol 182: 685-701, 2008.

18. Hayashi-Nishino M, Fujita N, Noda T, Yamaguchi A, Yoshimori T and Yamamoto A: A subdomain of the endoplasmic reticulum forms a cradle for autophagosome formation. Nat Cell Biol 11: 1433-1437, 2009

19. Hailey DW, Rambold AS, Satpute-Krishnan P, Mitra K, Sougrat R, Kim PK and Lippincott-Schwartz J: Mitochondria supply membranes for autophagosome biogenesis during starvation. Cell 141: 656-667, 2010.

20. Tooze SA and Yoshimori T: The origin of the autophagosomal membrane. Nat Cell Biol 12: 831-835, 2010

21. Ravikumar B, Moreau K, Jahreiss L, Puri C and Rubinsztein DC: Plasma membrane contributes to the formation of pre-autophagosomal structures. Nat Cell Biol 12: 747-757, 2010.

22. Goligorsky MS: SIRTing out the link between autophagy and ageing. Nephrol Dial Transplant 25: 2434-2436, 2010.

23. Schrijvers DM, De Meyer GR and Martinet W: Autophagy in atherosclerosis: a potential drug target for plaque stabilization. Arterioscler Thromb Vasc Biol 31: 2787-2791, 2011.

24. Martinet W and De Meyer GR: Autophagy in atherosclerosis: a cell survival and death phenomenon with therapeutic potential Circ Res 104: 304-317, 2009

25. Martinez J, Almendinger J, Oberst A, Ness R, Dillon CP, Fitzgerald P, Hengartner MO and Green DR: Microtubuleassociated protein 1 light chain 3 alpha (LC3)-associated phagocytosis is required for the efficient clearance of dead cells. Proc Natl Acad Sci USA 108: 17396-17401, 2011.
26. Yu W, Fu YC, Chen CJ, Wang X and Wang W: SIRT1: a novel target to prevent atherosclerosis. J Cell Biochem 108: 10-13, 2009.

27. Norata GD, Marchesi P, Passamonti S, Pirillo A, Violi F and Catapano AL: Anti-inflammatory and anti-atherogenic effects of cathechin, caffeic acid and trans-resveratrol in apolipoprotein $\mathrm{E}$ deficient mice. Atherosclerosis 191: 265-271, 2007.

28. Wang Z, Zou J, Cao K, Hsieh TC, Huang Y and Wu JM Dealcoholized red wine containing known amounts of resveratrol suppresses atherosclerosis in hypercholesterolemic rabbits without affecting plasma lipid levels. Int J Mol Med 16: 533-540, 2005.

29. Zhang QJ, Wang Z, Chen HZ, Zhou S, Zheng W, Liu G, Wei YS, Cai H, Liu DP and Liang CC. Endothelium-specific overexpression of class III deacetylase SIRT1 decreases atherosclerosis in apolipoprotein E-deficient mice. Cardiovasc Res 80: 191-199, 2008.

30. Li L, Zhang HN, Chen HZ, Gao P, Zhu LH, Li HL, Lv X, Zhang QJ, Zhang R, Wang Z, She ZG, Zhang R, Wei YS, Du GH, Liu DP and Liang CC: SIRT1 acts as a modulator of neointima formation following vascular injury in mice. Circ Res 108: 1180-1189, 2011.

31. Houtkooper RH, Pirinen E and Auwerx J: Sirtuins as regulators of metabolism and healthspan. Nat Rev Mol Cell Biol 13: 225-238, 2012

32. Mattagajasingh I, Kim CS, Naqvi A, Yamamori T, Hoffman TA, Jung SB, DeRicco J, Kasuno K and Irani K: SIRT1 promotes endothelium-dependent vascular relaxation by activating endothelial nitric oxide synthase. Proc Natl Acad Sci USA 104: 14855-14860, 2007.

33. Brunet A, Sweeney LB, Sturgill JF, Chua KF, Greer PL, Lin Y, Tran H, Ross SE, Mostoslavsky R, Cohen HY, Hu LS, Cheng HL, Jedrychowski MP, Gygi SP, Sinclair DA, Alt FW and Greenberg ME: Stress-dependent regulation of FOXO transcription factors by the SIRT1 deacetylase. Science 303: 2011-2015, 2004.

34. Stein S and Matter CM: Protective roles of SIRT1 in atherosclerosis. Cell Cycle 10: 640-647, 2011.

35. Lee IH, Cao L, Mostoslavsky R, Lombard DB, Liu J, Bruns NE, Tsokos M, Alt FW and Finkel T: A role for the NAD-dependent deacetylase Sirt1 in the regulation of autophagy. Proc Natl Acad Sci USA 105: 3374-3379, 2008.

36. Kockx MM, De Meyer GR, Buyssens N, Knaapen MW, Bult H and Herman AG: Cell composition, replication, and apoptosis in atherosclerotic plaques after 6 months of cholesterol withdrawal. Circ Res 83: 378-387, 1998

37. Nowicki M, Zabirnyk O, Duerrschmidt N, Borlak J and Spanel-Borowski K: No upregulation of lectin-like oxidized low-density lipoprotein receptor-l in serum-deprived EAhy926 endothelial cells under oxLDL exposure, but increase in autophagy. Eur J Cell Biol 86: 605-615, 2007.

38. Yoshimori T: Autophage: a regulated bulk degradation process inside cells. Biochem Biophys Res Commm 313: 453-458, 2004.

39. Singh R and Cuervo AM: Autophagy in the cellular energetic balance. Cell Metab 13: 495-504, 2011.

40. Singh R, Kaushik S, Wang Y, Xiang Y, Novak I, Komatsu M, Tanaka K, Cuervo AM and Czaja MJ: Autophagy regulates lipid metabolism. Nature 458: 1131-1135, 2009.

41. Singh R and Cuervo AM: Lipophagy: connecting autophagy and lipid metabolism. Int J Cell Biol 2012: 282041, 2012

42. Liu K and Czaja MJ: Regulation of lipid stores and metabolism by lipophagy. Cell Death Differ 20: 3-11, 2013.

43. Ouimet M, Franklin V, Mak E, Liao X, Tabas I and Marcel YL: Autophagy regulates cholesterol efflux from macrophage foam cells via lysosomal acid lipase. Cell Metab 13: 655-667, 2011

44. Kiffin R, Bandyopadhyay U and Cuervo AM: Oxidative stress and autophagy. Antioxid Redox Signal 8: 152-162, 2006.

45. Ohsumi Y: Molecular dissection of autophagy: two ubiquitin-like systems. Nat Rev Mol Cell Biol 2: 211-216, 2001.

46. Shintani T and Klionsky DJ: Autophagy in health and disease: a double-edged sword. Science 306: 990-995, 2004.

47. Lum JJ, DeBerardinis RJ and Thompson CB: Autophagy in metazoans: cell survival in the land of plenty. Nat Rev Mol Cell Biol 6: 439-448, 2005.

48. Li S, Sun Y, Liang CP, Thorp EB, Han S, Jehle AW, Saraswathi V, Pridgen B, Kanter JE, Li R, Welch CL, Hasty AH, Bornfeldt KE, Breslow JL, Tabas I and Tall AR: Defective phagocytosis of apoptotic cells by macrophages in atherosclerotic lesions of ob/ob mice and reversal by a fish oil diet. Circ Res 105: 1072-1082, 2009. 
49. Yancey PG, Blakemore J, Ding L, Fan D, Overton CD, Zhang Y, Linton MF and Fazio S: Macrophage LRP-1 controls plaque cellularity by regulating efferocytosis and Akt activation. Arterioscler Thromb Vasc Biol 30: 787-795, 2010.

50. Jehle AW, Gardai SJ, Li S, Linsel-Nitschke P, Morimoto K, Janssen WJ, Vandivier RW, Wang N, Greenberg S, Dale BM, Qin C, Henson PM and Tall AR: ATP-binding cassette transporter A7 enhances phagocytosis of apoptotic cells and associated ERK signaling in macrophages. J Cell Biol 174: 547-556, 2006.

51. He X, Andersson G, Lindgren U and Li Y: Resveratrol prevents RANKL-induced osteoclast differentiation of murine osteoclast progenitor RAW 264.7 cells through inhibition of ROS production. Biochem Biophys Res Commun 401: 356-362, 2010.

52. Peled T, Shoham H, Aschengrau D, Yackoubov D, Frei G Rosenheimer GN, Lerrer B, Cohen HY, Nagler A, Fibach E and Peled A: Nicotinamide, a SIRT1 inhibitor, inhibits differentiation and facilitates expansion of hematopoietic progenitor cells with enhanced bone marrow homing and engraftment. Exp Hematol 40: 342-355, 2012.

53. Zhang JG, Zhao G, Qin Q, Wang B, Liu L, Liu Y, Deng SC, Tian K and Wang CY: Nicotinamide prohibits proliferation and enhances chemosensitivity of pancreatic cancer cells through deregulating SIRT1 and Ras/Akt pathways. Pancreatology 13: 140-146, 2013.
54. Stein S, Lohmann C, Schäfer N, Hofmann J, Rohrer L, Besler C, Rothgiesser KM, Becher B, Hottiger MO, Borén J, McBurney MW, Landmesser U, Lüscher TF and Matter CM: SIRT1 decreases Lox-1-mediated foam cell formation in atherogenesis. Eur Heart J 31: 2301-2309, 2010.

55. Guarente L: Franklin H. Epstein Lecture: Sirtuins, aging, and medicine. N Engl J Med 364: 2235-2244, 2011.

55. Chen Lf, Fischle W, Verdin E and Greene WC: Duration of nuclear NF-kappaB action regulated by reversible acetylation. Science 293: 1653-1657, 2001

57. Albani D, Polito L, Batelli S, De Mauro S, Fracasso C, Martelli G, Colombo L, Manzoni C, Salmona M, Caccia S, Negro A and Forloni G: The SIRT1 activator resveratrol protects SK-N-BE cells from oxidative stress and against toxicity caused by alphasynuclein or amyloid-beta (1-42) peptide. J Neurochem 110 : 1445-1456, 2009.

58. Wu Y, Li X, Zhu JX, Xie W, Le W, Fan Z, Jankovic J and Pan T: Resveratrol-activated AMPK/SIRT1/autophagy in cellular models of Parkinson's disease. Neurosignals 19: 163-174, 2011.

59. Takeda-Watanabe A, Kitada M, Kanasaki K and Koya D: SIRT1 inactivation induces inflammation through the dysregulation of autophagy in human THP-1 cells. Biochem Biophys Res Commun 427: 191-196, 2012. 